\title{
TRABALHANDO COM HISTÓRIAS DE VIDA DE FAMILIARES DE PACIENTES PSIQUIÁTRICOS
}

\section{WORKING WITH LIFE HISTORIES OF PSYQUTATRIC PATIENTS' FAMILY MEMBERS}

\author{
Vera Lúcia Mendiondo Osinaga* \\ Maria Jésia Vieira** \\ Maria Vigonete Araújo Lima Armelin*** \\ Antonia Regina F. Furegato****
}

OSINAGA, V.L.M. et al. Trabalhando com histórias de vida de familiares de pacientes psiquiátricos. Rev.Esc.Enf.USP, v. 34, n.4, p. 401-6, dez. 2000.

\section{RESUMO}

Este texto contém o relato de uma experiência prática, de pesquisa, utilizando-se a teoria e as técnicas de história oral. As autoras apresentam os fundamentos teóricos e metodológicos da técnica, a escolha do tema que focalizou o paciente psiquiátrico e sua relação familiar, o local da pesquisa e a caracterização dos colaboradores. Apresentam cada passo desta metodologia desde a entrevista, leituras, transcrição, limpeza do texto, leitura flutuante, transcriação, identificação do tom vital e das categorias de análise. Finalmente, destacam as categorias subtraidas do relato, comentando os temas referentes a cada uma. A técnica mostrou-se eficaz para apreensão de categorias subjetivas e como fonte de compreensão das relações pessoais e sociais, no cotidiano da enfermagem em saúde mental.

PALAVRAS-CHAVE: História (Teorias). Técnica de pesquisa. Pacientes. Enfermagem Psiquiátrica.

\section{ABSTRACT}

This text contains the account of a practical research experience which uses the theory and techniques of oral narratives. The authors present the theoretical and methodological framework of the technique, the choice of the ,topic, which focused on the psychiatric patient and his/her family relationship, the research site and the characterization of collaborators. They also present each step of this methodology, starting from the interviews and following on to the reading, transcription, text correction, floating reading, trans-creation, identification of the vital tone as well as that of analysis categories. Finally, they point out the categories that have been removed from the account by making comments on the topics referring to each one. The technique was shown to be effective for the apprehension of subjective categories and as way to understand personal and social relationships in the everyday practice of nursing in mental health.

KEYWORDS: History (Theory). Research technique. Patients. Psychiatric Nursing.

\section{CONSIDERAÇÕES GERAIS}

No desenvolvimento do Programa de pós graduação em Enfermagem Psiquiátrica da Escola de Enfermagem de Ribeirão Preto, alguns pesquisadores sentiram a necessidade de estudar os fundamentos teóricos da história oral, assim como as estratégias metodológicas de coleta de dados em pesquisa, tendo em vista sua aplicabilidade para a enfermagem e suas relações.

* Enfermeira, mestranda do programa de Enfermagem Psiquiátrica e Ciências Humanas da EERP/USP.

** Enfermeira, Professora adjunta do Depto de Enfermagem e Nutrição do CCBS da Universidade Federal de Sergipe. Doutoranda do Programa Interunidades de Doutoramento em Enfermagem da USP/EERP, convênio UFBa.

*** Enfermeira, professora da Faculdade de Enfermagem e Obstetrícia de Fernandópolis, SP. Mestranda do programa de Enfermagem

Psiquiátrica e Ciências Humanas da EERP./USP.

**** Enfermeira: Prof. Titular do Depto de Enfermagem Psiquiátricas e Ciências Humanas da EERP/USP. 
A disciplina História Oral, foi ministrada com a colaboração do Professor Dr $^{\circ}$ José Carlos Sebe Bom Meihy da Faculdade de História, da Universidade de São Paulo. O professor Meihy tem se dedicado ao estudo da História Oral, tendo sistematizado este conhecimento, hoje reconhecido internacionalmente.

Esta disciplina ocorreu em 2 semestres consecutivos, em forma de módulos. Além do estudo teórico, desenvolveu-se uma proposta de experiência prática, para que todo o grupo tivesse oportunidade de vivenciar passo a passo tanto a coleta como a análise de dados, com base nesta metodologia.

A disciplina contou com a participação não só dos pós graduandos da área, como também dos outros programas da mesma Escola e inclusive de outras áreas do conhecimento, o que contribuiu para enriquecer a experiência, sendo também um indicativo do interesse teórico e metodológico. O grupo foi dividido em várias equipes.

O presente trabalho é o relato da trajetória metodológica de uma dessas equipes fundamentada nos elementos teóricos da história oral, seguindo a proposta de MEIHY (1996). Apresenta também os comentários sobre sua utilização como estratégia de coleta de dados em pesquisas, principalmente as que abordam categorias subjetivas ligadas à vivência das pessoas.

\section{FUNDAMENTAÇÃO TEÓRICA}

A história oral, como estratégia de captação de informações relativas a experiências vividas, sejam elas pessoais ou sociais, pressupõe o apoio de um referencial que não se alicerce na história tradicional dos fatos, das datas, dos personagens e dos heróis, mas na história como fruto de vivências de uma sociedade, onde cada um possa ter voz e vez, onde cada um pode ser protagonista, interlocutor e membro ativo.

A história oral, fundamentada na História Nova, que, conforme BURKE (1992), baseia-se no fato de que ela pode ser contada também a partir dos homens comuns, é uma "construção cultural, sujeita a variações, tanto no tempo quanto no espaço".

Ela se afirma, ainda segundo LE GOFF (1995), como uma história processual, de bastidores, construída, uma história das massas que leva em conta o contexto, as estruturas e a cultura dos povos.

Nesta perspectiva, a história pessoal, configura-se como parte da história social e serve de articulação para o entendimento de fatos e vivências de indivíduos e grupos, relativos às categorias subjetivas em estudo.
A história oral, ou história transmitida pela comunicação com as pessoas, é, conforme MEIHY(1996),

"um conjunto de procedimentos que se iniciam com a elaboração de um projeto e continuam com a definição de um grupo de pessoas (ou colônia) a serem entrevistadas, com o planejamento $e$ a condução das gravações, com a transcrição, com a conferência do depoimento, com a autorização para o uso, arquivamento e, sempre que possivel, com a publicação dos resultados que devem, em primeiro lugar, voltar ao grupo que gerou as entrevistas":

A utilização da história oral teve início na década de 40, nos Estados Unidos, e tomou impulso na década de 60. No Brasil, sua experiência de consolidação iniciou-se na década de 70 e tem tomado impulso nos últimos cinco anos (MEIHY, 1996).

O mesmo autor descreve três modalidades de história oral, das quais a primeira é denominada história oral de vida, que "diz respeito ao conjunto da experiência de vida de uma pessoa"(p.35), devendo o pesquisador colocar as perguntas ou temas de forma ampla, indicativa e em blocos. A segunda é a história oral temática onde se busca "o esclarecimento ou opinião do entrevistado sobre algum evento definido". A terceira é a tradição oral onde se buscam informações sobre "questões do passado longinquo que se manifestam pelo chamado folclore e pela transmissão geracional, de pais para filhos ou de individuos para indivíduos".

QUEIROZ (1983, 1988) refere-se à história de vida como situada na interface entre o individual e o social já que cada indivíduo que faz seu relato, tem não só a sua história pessoal, mas também uma percepção e uma representação próprias, sendo ainda um reflexo de seu tempo e espaço, com influências as mais diversas, constituindo, portanto, "uma unidade dentro da coletividade".

Todos os autores consultados são unânimes em ressaltar a necessária interação que deve existir entre o pesquisador e o entrevistado, que neste tipo de trabalho é denominado por MEIHY (1996) de "colaborador", pelo fato deste ser um participante ativo na pesquisa realizada, e não um mero respondente ou informante, embora todo o processo de condução e autoria do projeto seja do próprio pesquisador.

A escolha da amostra é intencional e depende da opção do pesquisador, tendo em vista o objeto a ser conhecido, a viabilidade e os custos. Geralmente, parte-se de alguma referência prévia com a intenção de se atingir a rede de informantes significativa para o objeto da pesquisa. 
Haverá tantos encontros quantos necessários ou convenientes para a obtenção dos dados, utilizando-se a sistemática de gravação da entrevista. Além disso, devem ser tomados outros cuidados como cópia da gravação em outra fita para evitar danos, extravios ou outras intercorrências; transcrição e conferência da fidedignidade; limpeza dos erros linguisticos e das repetições quando isto não prejudicar a caracterização da mesma; resumo dos pontos relevantes; retomada ao entrevistado para validação e autorização escrita de uso e publicação, podendo o mesmo vetar a revelação de parte ou do todo das informações de maneira definitiva ou por certo período .de tempo (MEIHY, 1994, 1996; QUEIROZ, 1983, 1988).

\section{METODOLOGIA}

Para participar desta experiência prática com história oral temática, cada grupo escolheu um de seus componentes para ser o entrevistador, ficando os outros encarregados de se juntarem a este para o processamento e a análise dos dados.

Sendo a maioria do grupo ligada à área de Enfermagem Psiquiátrica, o projeto previa a realização de entrevistas com familiares cuidadores de pacientes psiquiátricos, com o intuito de conhecer as relações destes familiares com o mesmo, assim como conhecer o que eles pensavam sobre a doença.

Por ser campo de estágio e pesquisa, foi escolhido o NAPS (Núcleo de Apoio Psico-Social), da Prefeitura Municipal de Ribeirão Preto. Este serviço é destinado a assistir pacientes com transtornos psiquiátricos, em regime ambulatorial, com equipe interdisciplinar.

Foram entrevistados familiares/cuidadores, previamente contatados pela Enfermeira responsável do Serviço. No lugar dos faltosos, foram incluídos outros familiares que compareceram ao Serviço, no horário marcado. Todos concordaram em participar da entrevista, através de Consentimento Esclarecido.

Foram explicados inicialmente, para todo o grupo de colaboradores, os objetivos e os procedimentos da entrevista, sendo-lhes garantida a privacidade e o sigilo da mesma, bem como seu direito de aceitar ou recusar-se a participar.

O entrevistador de cada grupo, dirigiu-se a uma sala com seu colaborador e propôs-lhe o seguinte: "Fale livremente sobre sua vida e sua relação com o seu familiar em tratamento'. A gravação foi disponibilizada para os que quiseram ouvir.

Terminada a entrevista, foram feitos comentários deste procedimento entre o grupo de entrevistadores e os coordenadores da experiência.
Voltando ao grande grupo, a experiência da entrevista foi socializada, inclusive com comentários sobre envolvimento, participação, interesse, emoção, dificuldades e facilidades na realização da mesma. Uma das dificuldades experimentadas foi em relação a não diretividade da entrevista, vez que tinha-se optado para que a mesma fosse livre. Outra dificuldade dizia respeito às emoções demonstradas por alguns colaboradores, as quais poderiam prejudicar a técnica caso o entrevistador se envolvesse. O grupo como um todo fez comentários gerais e pediu os esclarecimentos pertinentes para melhor compreender a técnica.

A seguir, cada grupo se recompôs em torno da respectiva entrevista para a fase de processamento dos dados. Inicialmente, foram feitas várias escutas da entrevista para entendê-la como um todo.

O passo seguinte foi a transcrição, transformando a fala em documento escrito para ser analisado. Seguindo a orientação metodológica, foi feita a limpeza dos erros linguísticos, repetições, tendo-se o cuidado de preservar o conteúdo original e o estilo de fala do colaborador.

Após este trabalho, foram feitas várias leituras flutuantes, a primeira das quais sem que se fizesse nenhuma interpretação ou anotação, e a seguir outras tantas para imergir neste conteúdo, buscando a compreensão da direção dada por cada colaborador à sua própria história. A este procedimento, MEIHY (1996) chama de "tom vital", ou seja, o tom específico que cada indivíduo dá à sua própria vida, o núcleo da sua narrativa. Nesta fase compreensiva do texto, foram examinadas e destacadas as categorias de análise, ou seja, os destaques de cada fala que serviam para o entendimento do conteúdo expresso pelas respectivos familiares.

De posse destes elementos, tom vital e categorias de análise, foi feita a transcriação da entrevista, um outro momento do método, tendo o pesquisador a liberdade de fazê-lo, já que foi previamente autorizado pelo colaborador. A trancriação é um recurso através do qual o pesquisador torna o conteúdo mais acessível à compreensão dos leitores, reelaborando o texto, dando-se especial relevância ao tom vital e às categorias mais expressivas da entrevista. $O$ texto resultante deve voltar ao colaborador para sua validação, o que foi feito, tendo sido ratificada esta autorização por cada um dos participantes.

O último passo foi a identificação das categorias e respectivos temas o que favoreceu sua apresentação comentada. 


\section{RESULTADOS E DISCUSSÃO}

O colaborador deste estudo, pai de um paciente psicótico, mostrou-se bastante receptivo em participar da experiência, e relatou de forma clara e objetiva sua história de vida, dando especial destaque à relação afetiva com o filho doente, caracterizada no tom vital de sua entrevista: " meu filho sofreudemais... mais do que eu... e acabou a mocidade nos hospitais... é isso que eu sinto... até que Jesus abençoou-o".

Este foi o tom vital que orientou o transcorrer do relato, emergindo do todo algumas categorias, apresentadas e discutidas no Quadro I, nas quais incluíram-se os temas identificados na história oral do familiar.

Quadro I - Categorias de análise e temas identificados, através da história oral de familiar de um paciente psiquiátrico

\begin{tabular}{|c|c|}
\hline A FAMÍLIA & $\begin{array}{l}\text { - Como um valor em si e para o paciente. Seu apoio é decisão em relação à manutenção } \\
\text { da vida e a busca de tratamento } \\
\text { - Centrada no filho doente } \\
\text { - Boas relações do doente com a família } \\
\text { - Medo da família em relação ao que pode acontecer durante as crises } \\
\text { - Sofrimento da família: choro, lembranças } \\
\text { - Doença da família provocada pela situação } \\
\text { - Internação como sofrimento para a família }\end{array}$ \\
\hline AMBIGÜIDADE & $\begin{array}{l}\text { - Valorizar as qualidades versus reconhecer seus desvios de conduta } \\
\text { - Sofrimento para a família } \\
\text { - Atribuir seus desvios de conduta à doença } \\
\text { - Conflitos entre se responsabilizar pela doença do filho versus dar tudo o que poderia } \\
\text { - Não entende onde falhou } \\
\text { - Medo da familia em relação ao que pode acontecer durante as crises }\end{array}$ \\
\hline O DOENTE & $\begin{array}{l}\text { Isolamento } \\
\text { - Inatividade } \\
\text { - Medo da morte } \\
\text { - Desconfiança } \\
\text { - Misantropia } \\
\text { Revolta com as internações } \\
\text { - Isolamento provocado pelas internações }\end{array}$ \\
\hline A DOENÇA & $\begin{array}{l}\text { - Sofrimento prolongado } \\
\text { - Doença com relação de causa-efeito } \\
\text { - Más companhias, drogas } \\
\text { - Doença com infelicidade } \\
\text { - Busca de tratamento } \\
\text { - Confiança na cura } \\
\text { - Internação como ambigüidade, como necessidade, como complicação e como } \\
\text { sofrimento }\end{array}$ \\
\hline O APOIO & $\begin{array}{l}\text { - Religião como suporte Igreja } \\
\text { - Instituição como apoio - NAPS } \\
\text { - Ajuda do amigo } \\
\text { - Sugestão do médico }\end{array}$ \\
\hline
\end{tabular}

\section{A FAMília}

A principal categoria identificada foi a família. A ela é atribuído um valor em si mesmo, e um valor para o paciente, já que seu apoio é decisivo tanto no que diz respeito à relação afetiva, quanto à busca e acompanhamento do tratamento, salientando ainda seu valor em relação à manutenção da vida. Este 404 aspecto é ressaltado pelo colaborador quando cita, em determinado momento: "se eu não fosse um pai que apoiasse, ele já teria morrido!... porque a maioria dos amigos dele morreram todos": Vale explicar aqui que o paciente do qual estamos falando foi usuário de drogas. 
Nesta entrevista, depreende-se que a família, enquanto núcleo que reside no mesmo espaço físico, é centrada na pessoa do doente e na sua doença. $O$ doente é o centro das atenções e, de certa forma, procura chamar a família para si, o que se pode confirmar na fala: "ele fica chamando a mãe o tempo todo: oh! Mãe, me dá isso, oh! Mãe, me dá aquilo. Agora, quem mais acompanha sou eu, porque tenho mais tempo".

Durante toda a entrevista, o colaborador fez questão de salientar as boas relações que o doente estabelece com a família, mas ao mesmo tempo emociona-se, chegando às lágrimas, ao falar na doença como sofrimento para todos, principalmente nos momentos de internação. Lembra também com grande sofrimento as crises, onde o paciente se mostra agressivo, desconhecendo inclusive os familiares. Fala ainda do medo da familia em relação ao que pode acontecer durante as crises, havendo, inclusive tentativas de agressão pelo paciente e ameaças contra a vida das pessoas que convivem com ele. Neste mesmo sentido, refere-se ao rapaz como causa de outras doenças na família, citando sua esposa que além de "esgotamento nervoso" pelo sofrimento e o medo, também se desgasta com o trabalho doméstico e as constantes solicitações e imposições do filho.

\section{AMBIGÜIDADE}

O colaborador expressou com muita clareza o sentimento de ambigüidade da família em relação ao doente mental, colocando-se todo o tempo entre o amor e o sofrimento; entre a valorização das qualidades do mesmo e o problema dos seus desvios de conduta; entre considerar o filho como uma benção e ao mesmo tempo considerar que o sofrimento que ele causa, é desgastante para a familia, chegando a provocar doenças. Refere-se muitas vezes ao amor que o filho tem pela familia e, ao mesmo tempo, fala do medo do que ele possa fazer durante as crises, referindo-se a episódios anteriores de agressão e ameaças de morte. Toda a sua fala era entrecortada pela conjunção "mas". "A mãe fica irritada de tanto lidar com ele, está até com esgotamento nervoso, mas não que ele seja ruim, ele é m menino maravilhoso":

Ainda em relação à ambigüidade, o informante procura justificar-se o tempo todo no que diz respeito ao seu relacionamento com o filho e ao questionamento de seu grau de envolvimento com as causas do problema: "Eu ajudei demais, eu ajudei demais ele; fiz tudo o que podia e não podia, como pai. Eu apoiei demais, tanto eu como a mãe"(...) "iniciou a vida muito bem, estava encaminhado, ai vieram os amigos. Fiz tudo de bom para o ... dei tudo o que ele precisava. A menina não deu trabalho, já nasceu e foi seguindo a vida dela..."
Fica evidente o desespero desse pai por não saber a quem atribuir a "desgraça que recai sobre sua familia', ora responsabilizando os amigos, ora como fatalidade.

\section{O DOENTE}

A terceira categoria identificada foi o doente, ou seja, como a família vê aquele doente mental, através do que se reflete o pensamento e a convivência social com outros doentes.

O colaborador refere-se ao isolamento do filho "ele gosta de ficar deitado... isolado...", à inatividade "não tem disposição para nada", ao medo da morte e à desconfiança, tanto em relação aos outros, quanto à própria família "ele só confia em nós. Ele confia desconfiando". $O$ pai relata comportamentos de misantropia, dizendo que o mesmo não quer saber de ninguém, não fala com ninguém, não freqüenta nada que lhe seja sugerido, a não ser a igreja. Fala ainda do mesmo como vítima que se encontra revoltado por tudo o que teve de sofrer com as internações, pelo isolamento a que teve que se submeter no hospital e os tratamentos recebidos. Esta internação também é vista como causa de piora para o paciente e de sofrimento para a família.

Mantém uma postura de vítima, dependente da familia, sem que lhe sejam cobradas atitudes de luta pela sobrevivência e muito menos de sua inserção na sociedade, como elemento produtivo e responsável. Vive alienado da cultura, e, portanto, não-humano, no sentido comum da cultura. Assim, pode ser excluído, mantendo o direito de continuar com sua maneira singular de viver.

\section{A DOENÇA}

Uma outra categoria identificada foi a caracterização da doença em si. Ela é vista como um mal, causa de sofrimento prolongado para o doente e para a família, e mais uma vez é ressaltado o sofrimento do doente. A doença é considerada como uma infelicidade. Entretanto, aqui, observa-se uma ambigüidade, quando o mesmo se refere à religião, que, procurada para resolver o sofrimento do filho, serviu para que a família passasse a vê-lo como uma benção "ele é um menino abençoado. Acho que Jesus abençoou nós':

A doença é vista também como relação de causa e efeito, quando o pai se refere às más companhias e às drogas a que os primeiros o induziram. Por outro lado, fala na doença como decorrente da "cabeça dele", e como ausência de forças ou condições para levar uma vida "normal". Isto fica mais evidente quando o colaborador compara os dois filhos, sendo um deles sadio. A doença; esta fatalidade, não lhe 
permitiu levar uma vida normal e, como conseqüência, conduziu-o às drogas, fechando o círculo das possibilidades.

Toda vez que fala na doença, refere-se à busca constante de tratamento e à confiança na cura. Entretanto, a internação aparece novamente de forma ambigua, considerando-a ao mesmo tempo como uma necessidade para o tratamento, e como causa da piora do quadro, vez que a medicação psiquiátrica que o impregnava, deixava-o cada vez mais alheio ao convivio social, trazendo angústia e sofrimento para a família. A internação também é vista como reclusão, segregação do seu ambiente e normatização excessiva. A doença, enfim, tem uma representação polarizada entre o mal e o bem decorrentes; entre as causas sociais e materiais, as drogas; entre o exógeno e o endógeno; e, o tratamento hospitalar como uma necessidade e como agravamento do quadro.

\section{O APOIO}

Como última categoria, identificamos o apoio que por sua vez tem relação com as outras categorias. Fala principalmente do apoio da religião, considerada como única possibilidade de superar o sofrimento, e como uma benção em relação ao tratamento. "Desde que ele começou a ir para a Igreja nunca mais teve crise. Para ele a religião foi uma glória" Esta influência da religião é extensiva à família à qual já nos referimos anteriormente. Como suporte social faz referência a um amigo que lhe sugeriu o NAPS como possibilidade de acompanhamento e tratamento. Este amigo é freqüentador desta mesma instituição psiquiátrica, que já havia sido sugerida por um dos médicos que o atendera, mas não houve receptividade da parte do paciente.

Quanto à instituição hospitalar de internação, sua conotação é de que seja necessária mas prejudicial e causadora de sofrimento.

O pai coloca em destaque o apoio da familia, no tratamento, na afetividade, na vida como um todo e na religião, que considera o maior suporte social e espiritual.

Percebe-se uma intersecção entre todas as categorias identificadas, seja no movimento de complementaridade, seja no de ambigüidade. O grupo avaliou a situação de trabalho com história de vida como uma experiência valiosa na apreensão das categorias subjetivas, entre elas, as que nos propusemos a estudar, ou seja, a relação familiar com o paciente psiquiátrico e os sentimentos destes familiares em relação ao doente e a sua doença.

\section{CONSIDERAÇÕES FINAIS}

Os estudos de história oral, além do conhecimento teórico, deram oportunidade de se experienciar e avaliar todos os passos da metodologia, além de ter oportunizado um exercício de análise qualitativa de entrevistas.

Entendemos que as categorias identificadas a partir da metodologia poderão, conforme os objetivos propostos em trabalho específico, serem discutidas com base em referencial teórico relativo às questões psiquiátricas e de saúde mental, o que não foi o objetivo do presente estudo.

Nossa pretensão foi apenas relatar a experiência de trabalhar com uma metodologia, entre outras, que se mostrou eficaz na apreensão de categorias subjetivas, não só em relação à história em si, mas também às relações sociais, familiares, sentimentos, ambigüidades, conceitos, crenças e suporte emocional.

Sua utilização como estratégia metodológica para a enfermagem é uma importante fonte de apreensão da história pessoal, inserida no social, a qual traz uma marca específica, já que situada no tempo, no espaço concreto e nos sistemas que orientam a cultura dos povos. Sendo assim, é um instrumento que pode ajudar na compreensão de contextos sócio-culturais mais amplos da história e das representações de seus membros, no cotidiano.

\section{REFERÊNCIAS BIBLIOGRÁFICAS}

BURKE, P. A escrita da história: novas perspectivas. Trad. de Magda Lopes. 2. ed. São Paulo, UNESP, 1992. 354p.

LE GOFF, J. A história nova. Trad. de Eduardo Brandão 3.ed. São Paulo, Martins Fontes, 1995. 318p.

MEIHY, J. C. S. B. Definindo história oral e memória. Cadernos CERU, v. 5 s.2, p.52-60, 1994.

Manual de história oral. São Paulo, Loyola, 1996. 78p.

QUEIROZ, M. I. P. Variações sobre a técnica de gravador no registro da informação viva. 2.ed. São Paulo, CERU e FFLCH/USP, 1983. (col.textos, 4)

. Relatos orais: do "indizivel" ao "dizivel". In: VON SIMON, O. de M. (org.) Experimentos com história de vida (Itália Brasil) São Paulo, Revista dos tribunais, 1988. p.14-43. 